\title{
The role of hydrogen metabolism in photoheterotrophic cultures of the cyanobacterium Nostoc sp. strain Ce isolated from Cycas circinalis $\mathrm{L}$.
}

\author{
Mario R. Tredici,* Maria C. Margheri, Roberto De PhilipPis and RicCardo Materassi \\ Centro di Studio dei Microrganismi Autotrofi, CNR, P. le delle Cascine, 27-50144 Firenze, Italy
}

(Received 27 April 1989; revised 19 February 1990; accepted 1 March 1990)

\begin{abstract}
As observed for other cyanobacteria, net $\mathrm{H}_{2}$ formation or consumption in photoheterotrophic, $\mathrm{N}_{2}$-fixing cultures of Nostoc sp. strain Cc, a cyanobacterium isolated from Cycas circinalis, was markedly dependent on the nickel ion content of the growth medium. Mean hydrogen consumption in the light of nickel-supplemented cultures, containing DCMU (3-(3,4-dichlorophenyl)-1,1-dimethylurea) and glucose (photoheterotrophic conditions), was about 10 times higher than in control cultures supplemented with DCMU, but lacking glucose. Uptake of exogenous $\mathrm{H}_{2}$ did not influence growth or glucose consumption, but significantly increased acetylene reduction and the total $\mathrm{N}$-content of the biomass, as well as ammonia excretion. It is postulated that the $\mathrm{H}_{2}$ uptake capability of the cyanobiont, and hence the nickel ion availability in the plant roots, may be important for the efficiency of $\mathrm{N}_{2}$ assimilation in plant-cyanobacteria symbioses.
\end{abstract}

\section{Introduction}

The evolution of $\mathrm{H}_{2}$ which is associated with the reduction of $\mathrm{N}_{2}$ to $\mathrm{NH}_{3}$ by the enzyme complex nitrogenase increases the energy costs of the $\mathrm{N}_{2}$ fixation process considerably and seems to be without any known benefit (Mortenson \& Thorneley, 1979; Stouthamer et $a l .$, 1988). However, many $\mathrm{N}_{2}$-fixing micro-organisms are capable of synthesizing a $\mathbf{H}_{2}$-oxidizing system, termed 'uptake' hydrogenase, which can recycle some or all of the $\mathrm{H}_{2}$ released by nitrogenase, and which is thought to confer important advantages to the organism, including the recovery of ATP and reductant, the protection of nitrogenase from $\mathrm{O}_{2}$ damage, and the removal of $\mathrm{H}_{2}$ itself which is considered to be a competitive inhibitor of $\mathrm{N}_{2}$ fixation (Dixon, 1972; Lambert \& Smith, 1981; Houchins, 1984).

All heterocystous cyanobacteria examined possess an active $\mathrm{H}_{2}$ uptake system which has been amply studied and characterized (Tel-Or et al., 1977; Lambert \& Smith, 1981; Houchins, 1984; Papen et al., 1986). However, the relationship of $\mathrm{H}_{2}$ metabolism to organic carbon utilization in cyanobacteria has been little investigated, since most studies have been done with obligate autotrophs (Houchins, 1984).

To shed some light on the potential benefit of $\mathrm{H}_{2}$ recycling in a facultative photo- and chemoheterotrophic

Abbreviation: DCMU, 3-(3,4-dichlorophenyl)-1,1-dimethylurea. cyanobacterium, we have studied the $\mathrm{H}_{2}$ exchange capability and the effect of $\mathrm{H}_{2}$ utilization on $\mathrm{N}_{2}$ fixation under photoheterotrophic conditions in Nostoc sp. strain $\mathrm{Cc}$, a free-living cyanobiont isolated from Cycas circinalis $\mathrm{L}$.

\section{Methods}

Organism and culture conditions. Nostoc sp. strain Cc (deposited in the Sammlung von Algenkulturen, Göttingen, FRG, as SAG 29.90), a cyanobacterial strain isolated from the coralloid roots of Cycas circinalis L. and rendered axenic in this laboratory, was grown in BG-11 medium (Rippka et al., 1979), buffered with $0.5 \mathrm{~g} \mathrm{HEPES} 1^{-1}(\mathrm{pH} 7 \cdot 5)$, photoautotrophically or photoheterotrophically (12 mM-glucose and $20 \mu \mathrm{M}-\mathrm{DCMU}$ ) under the conditions described previously (Tredici $e t$ $a l,, 1988 a$ ). When required, $\mathrm{NiCl}_{2}$ was added to a concentration of $1.3 \mu \mathrm{M}$. The purity of the cultures prior to, and in the course of, experiments was ascertained by phase-contrast microscopy.

Assay conditions. Experimental assays were done in borosilicate glass vials $(38 \mathrm{ml})$ containing samples $(15 \mathrm{ml})$ of photoheterotrophic or photoautotrophic cultures, at an initial cell concentration ranging from $360-450 \mathrm{mg}$ dry wt $1^{-1}$ (unless otherwise stated). At the time of sampling for the assays, the glucose concentration in the photoheterotrophic cultures was adjusted to about 6.5-7.5 mM. Photoautotrophic cultures at the onset of assays were supplemented with $20 \mu \mathrm{M}$-DCMU and were considered as controls. The vials were flushed with a gas mixture containing $(\%, v / v)$ either $\mathrm{H}_{2}(10 \cdot 5), \mathrm{O}_{2}(12 \cdot 2), \mathrm{CO}_{2}(1 \cdot 3), \mathrm{N}_{2}$ (76.0) or $\mathrm{O}_{2}(12 \cdot 5), \mathrm{CO}_{2}(1 \cdot 3), \mathrm{N}_{2}(86 \cdot 2)$. They were then hermetically sealed with butyl rubber septa (Pierce) and incubated, for the periods indicated, in a Gallenkamp orbital incubator at $30 \pm 0.5^{\circ} \mathrm{C}$ under continuous illumination provided by cool white fluorescent tubes at an incident photon flux rate of $80 \mu \mathrm{E} \mathrm{m}^{-2} \mathrm{~s}^{-1}$. 


\begin{abstract}
Analytical methods. $\mathrm{H}_{2}$ and $\mathrm{O}_{2}$ exchange was measured by withdrawing gas samples $(0.1 \mathrm{ml})$ from the assay vessels and injecting them into a Fractovap model 2150 gas chromatograph (Carlo Erba Strumentazione) fitted with a $0.5 \mathrm{~nm}$ molecular sieve column and a thermal conductivity detector. Nitrogenase activity was assayed by the $\mathrm{C}_{2} \mathrm{H}_{2}$ reduction technique (Turner \& Gibson, 1980). $\mathrm{C}_{2} \mathrm{H}_{2}(2.5 \mathrm{ml}$ ) was introduced into the experimental vessels at different time intervals without reflushing them. Ethylene evolution was measured after $1 \mathrm{~h}$ of incubation under the light and temperature regimes described above. Growth was monitored by determining the cellular dry weight of the cultures. The whole biomass of a vial was collected by filtration through a Sartorius membrane filter $(5 \mu \mathrm{m})$, which was then washed with $\mathrm{H}_{2} \mathrm{O}$ and dried at $70^{\circ} \mathrm{C}$ to constant weight. The elemental composition was determined by means of an automatic Elemental Analyzer (Carlo Erba Strumentazione, model 1106) as reported previously (Tredici $e t$ al., $1988 a$ ). Glucose concentration in the medium was measured spectrophotometrically at $340 \mathrm{~nm}$ by a coupled enzymic reaction, in which glucose is first phosphorylated by hexokinase in the presence of ATP; the glucose 6-phosphate generated is then quantified from the amount of NADP reduced by glucose-6-phosphate dehydrogenase (Methods of Enzymatic Food Analysis, 1984). The ammonium content of the medium was measured by the Nessler method after the cells had been removed by filtration. Growth, glucose consumption, nitrogenase activity and gas exchange were determined daily. The amount of ammonium nitrogen excreted and the elemental composition of the biomass were measured at the end of the experiments. All determinations were made on at least three replicate cultures.
\end{abstract}

\section{Results}

\section{Hydrogen metabolism of Nostoc sp. strain Cc grown in media with and without added nickel}

Nostoc sp. strain Cc, grown photoheterotrophically in BG- $11_{0}$ medium without added nickel and under a gas phase of initial composition $(\%, \mathrm{v} / \mathrm{v}) \mathrm{O}_{2}(12 \cdot 5), \mathrm{CO}_{2}(1 \cdot 3)$, $\mathrm{N}_{2}(86 \cdot 2)$, evolved $\mathrm{H}_{2}$ throughout the growth period (Table 1). From the rates of $\mathrm{C}_{2} \mathrm{H}_{2}$ reduction determined on the same cultures and under the same gas phase
(Table 1) it was calculated that $\mathrm{H}_{2}$ evolution was equivalent to $11 \cdot 6-39.4 \%$ of the electrons flowing through nitrogenase. Addition of $\mathrm{NH}_{4} \mathrm{Cl}(10 \mathrm{mM})$ to the growth medium at the time of sampling for the assays greatly reduced $\mathrm{C}_{2} \mathrm{H}_{2}$ reduction and completely abolished $\mathrm{H}_{2}$ evolution (Table 1). This implies that nitrogenase mediates $\mathrm{H}_{2}$ evolution and excludes the possibility that glucose stimulates the synthesis and/or activity of a reversible hydrogenase. However, the mean specific rates of $\mathrm{H}_{2}$ evolution varied considerably in independent experiments, irrespective of the initial and final biomass concentrations (Fig. 1). This is in contrast to the rates of

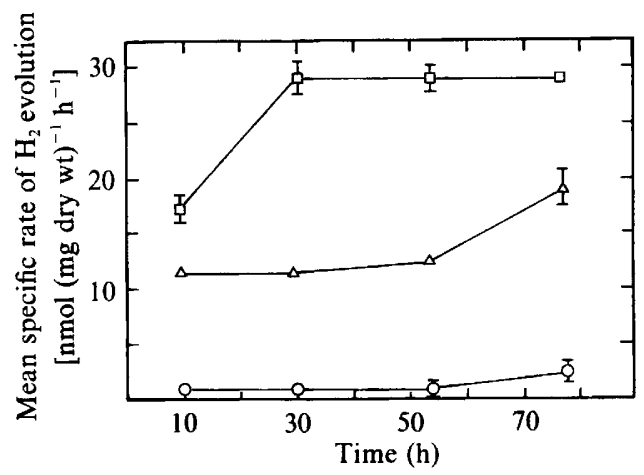

Fig. 1. Variation of mean specific rates of $\mathbf{H}_{2}$ evolution in three independent experiments done on photoheterotrophic cultures of Nostoc sp. strain Cc grown in media without added nickel. The cell concentration, over the whole period of growth investigated (from the onset of the experiment to the exhaustion of glucose in the medium), varied from $370-1115 \mathrm{mg}$ (dry wt) $\mathrm{l}^{-1}(\triangle)$; from $445-1170 \mathrm{mg}$ (dry wt) $\mathrm{I}^{-1}(O)$, and from $800-1840 \mathrm{mg}$ (dry wt) $\mathrm{l}^{-1}(\square)$. The high yield of dry weight in the latter experiment was achieved by re-addition of glucose (about $8 \mathrm{~mm}$ ) shortly before the glucose supplied at time zero had been totally consumed. Experiments were done under a gas phase of initial composition $(\%, \mathrm{v} / \mathrm{v}) \mathrm{O}_{2}(12 \cdot 5), \mathrm{CO}_{2}(1 \cdot 3), \mathrm{N}_{2}(86 \cdot 2)$. The values reported are the means of at least three replicates. Standard error bars are not shown when smaller than the dimensions of the symbols. Further details of culture conditions are described in Methods.

\section{Table $1 . \mathrm{H}_{2}$ evolution and $\mathrm{C}_{2} \mathrm{H}_{2}$ reduction activity of photoheterotrophic cultures of}

$$
\text { Nostoc sp. strain Cc }
$$

Nostoc sp. strain Cc was grown in media without added nickel in the presence and absence of combined nitrogen. Values reported are the means calculated for the time intervals indicated on at least three replicate cultures $( \pm \mathrm{SE}) . \mathrm{NH}_{4} \mathrm{Cl}(10 \mathrm{mM})$ was added at time zero of the experiment. The assays were done under a gas phase of initial composition $(\%, v / v) \mathrm{O}_{2}(12 \cdot 5), \mathrm{CO}_{2}(1 \cdot 3), \mathrm{N}_{2}(86 \cdot 2)$. Details of culture conditions are described in Methods.

\begin{tabular}{|c|c|c|c|c|}
\hline \multirow{2}{*}{$\begin{array}{l}\text { Time interval from } \\
\text { the onset of the } \\
\text { experiment }(\mathrm{h})\end{array}$} & \multicolumn{2}{|c|}{$\begin{array}{l}\text { Mean specific rate of } \mathrm{H}_{2} \text { evolution } \\
{\left[\mathrm{nmol}(\mathrm{mg} \text { dry } \mathrm{wt})^{-1} \mathrm{~h}^{-1}\right]}\end{array}$} & \multicolumn{2}{|c|}{$\begin{array}{l}\text { Mean } \mathrm{C}_{2} \mathrm{H}_{2} \text { reduction activity } \\
{\left[\mathrm{nmol}(\mathrm{mg} \text { dry } \mathrm{wt})^{-1} \mathrm{~h}^{-1}\right]}\end{array}$} \\
\hline & $\begin{array}{l}\text { Without combined } \\
\text { nitrogen }\end{array}$ & $+10 \mathrm{mM}-\mathrm{NH}_{4} \mathrm{Cl}$ & $\begin{array}{l}\text { Without combined } \\
\text { nitrogen }\end{array}$ & $+10 \mathrm{mM}^{-\mathrm{NH}_{4} \mathrm{Cl}}$ \\
\hline $0-18$ & $11 \cdot 3 \pm 0.5$ & $0.2 \pm 0.1$ & $73.8 \pm 1.4$ & Not determined \\
\hline $18-42$ & $11 \cdot 7 \pm 0.5$ & 0.0 & $100 \cdot 5 \pm 1 \cdot 6$ & $6 \cdot 1 \pm 0.5$ \\
\hline $42-66$ & $12.5 \pm 0.5$ & 0.0 & $80 \cdot 4 \pm 1 \cdot 3$ & $2 \cdot 5 \pm 0.5$ \\
\hline $66-90$ & $19 \cdot 0 \pm 1.5$ & 0.0 & $48 \cdot 2 \pm 1 \cdot 3$ & $0.2 \pm 0.1$ \\
\hline
\end{tabular}


$\mathrm{C}_{2} \mathrm{H}_{2}$ reduction which, within the range of $500-1000 \mathrm{mg}$ dry wt $1^{-1}$, were relatively reproducible $[65-100 \mathrm{nmol}$ (mg dry wt) ${ }^{-1} \mathrm{~h}^{-1}$ ] (data not shown).

Cultures supplemented with DCMU, but lacking glucose, never evolved $\mathrm{H}_{2}$ but consumed it when it was added to the gas phase (initial concentration $10.5 \%$, v/v) at a mean specific rate varying from 5-25 $\mathrm{nmol}$ (mg dry $w)^{-1} h^{-1}$ (data not shown).

When nickel $(1.3 \mu \mathrm{M})$ was added to photoheterotrophic cultures producing $\mathrm{H}_{2}$, net $\mathrm{H}_{2}$ production ceased and, after a lag of 4-8 h, $\mathrm{H}_{2}$ consumption was initiated (data not shown). The variability of the specific rate of $\mathrm{H}_{2}$ evolution observed in the experiments done without added nickel (Fig. 1) might therefore be due to different trace amounts of nickel ions in the medium at the time of sampling for the assays, since no precautions were taken to eliminate contaminant nickel from glassware, water and chemicals.

Effect of $\mathrm{H}_{2}$ consumption on growth and $\mathrm{N}_{2}$ fixation in photoheterotrophically grown Nostoc sp. strain Cc

To assess the role of $\mathrm{H}_{2}$ consumption during photoheterotrophic growth, Nostoc sp. strain Cc was grown in the light with glucose and DCMU in nickel-supplemented media, both in the presence and absence of $\mathrm{H}_{2}$ in the gas phase (Fig. 2)

Photoheterotrophic nickel-supplemented cultures of Nostoc sp. strain $\mathrm{Cc}$ consumed exogenous $\mathrm{H}_{2}$ at a mean specific rate, calculated for the entire growth period of $66 \mathrm{~h}$, of $159.8 \mathrm{nmol}(\mathrm{mg} \text { dry wt) })^{-1} \mathrm{~h}^{-1}$ (Table 2). The mean specific rate of $\mathrm{H}_{2}$ uptake over the same time period in the control cultures, containing DCMU but lacking glucose, was about 10 times lower (Table 2).

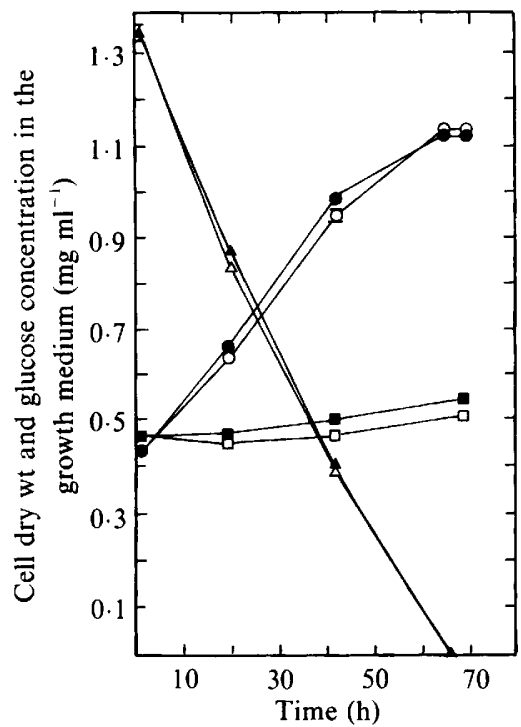

Fig. 2. Growth and glucose uptake of Nostoc sp. strain Cc grown photoheterotrophically in nickel-supplemented media with or without added $\mathbf{H}_{2}$ in the gas phase. $\bullet$, Growth of cultures supplemented with $\mathrm{H}_{2} ; \mathrm{O}$, growth of cultures in the absence of added $\mathrm{H}_{2} ; \Delta$, glucose consumption by cultures supplemented with $\mathrm{H}_{2} ; \triangle$, glucose consumption of cultures not supplemented with $\mathrm{H}_{2}$. Growth of controls in the presence of DCMU, but lacking glucose, with $(\mathbf{\square})$ and without $(\square)$ added $\mathrm{H}_{2}$ are also shown. The values illustrated are the means of at least three replicates. Standard error bars are not shown when smaller than the dimensions of the symbols. The results reported are typical of those obtained in three independent experiments. Details of culture conditions and composition of the gas phase are described in Methods.

Table 2. Growth parameters and gas exchange of photoheterotrophic cultures of Nostoc sp. strain Cc

Nostoc sp. strain Cc was grown in nickel-supplemented media with and without added $\mathrm{H}_{2}(10.5 \%, \mathrm{v} / \mathrm{v})$ in the gas phase; control cultures were supplemented with DCMU, but lacked glucose. Values $( \pm \mathrm{SE})$ reported are the means calculated for the whole growth period $(66 \mathrm{~h})$ illustrated in Figs $2-4$.

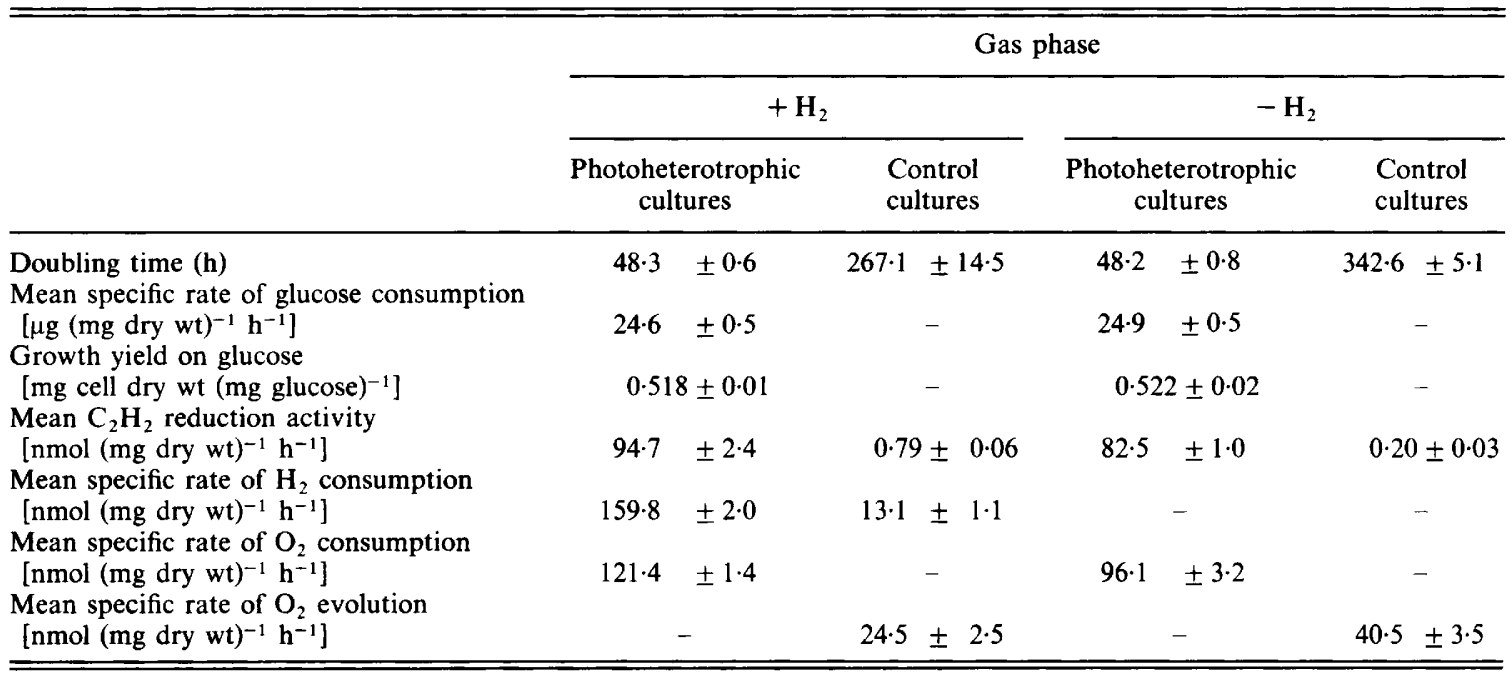




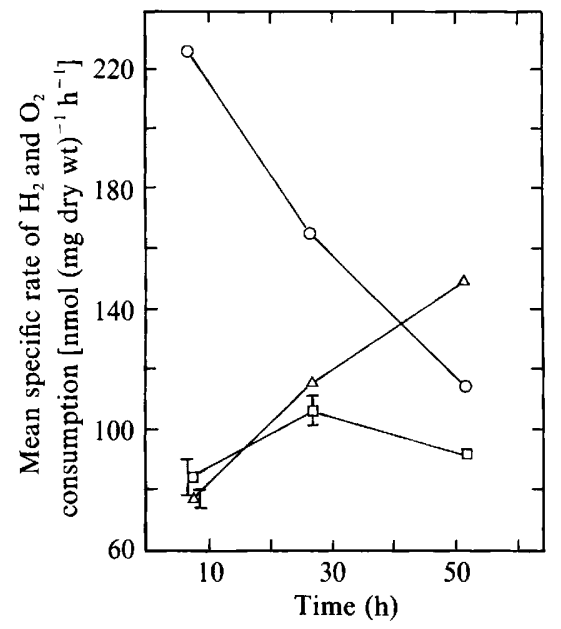

Fig. 3. Mean specific rates of $\mathrm{H}_{2}$ and $\mathrm{O}_{2}$ consumption of photoheterotrophic cultures of Nostoc sp. strain Cc assayed in nickel-supplemented media with or without added $\mathrm{H}_{2}$ in the gas phase. Mean specific rates of $\mathrm{H}_{2}(\mathrm{O})$ and $\mathrm{O}_{2}(\triangle)$ consumption of cultures supplemented with $\mathrm{H}_{2}$ are shown, together with the mean specific rate of $\mathrm{O}_{2}(\square)$ consumption of cultures in the absence of $\mathrm{H}_{2}$. The initial composition $(\%, v / v)$ of the gas phase was either $\mathrm{H}_{2}(10 \cdot 5), \mathrm{O}_{2}(12 \cdot 2), \mathrm{CO}_{2}(1 \cdot 3), \mathrm{N}_{2}(76.0)$ or $\mathrm{O}_{2}(12 \cdot 5), \mathrm{CO}_{2}(1 \cdot 3), \mathrm{N}_{2}(86 \cdot 2)$. The initial gas phase of the $\mathrm{H}_{2}$ supplemented cultures was restored at $42 \mathrm{~h}$ by reflushing the vessels. Growth and glucose consumption of the cultures are shown in Fig. 2. The values illustrated are the means of at least three replicates. Standard error bars are not shown when smaller than the dimensions of the symbols. The results reported are typical of those obtained in three independent experiments.

The theoretical energetic input that the Nostoc strain could derive from its rate of $\mathrm{H}_{2}$ uptake under photoheterotrophic conditions represents about $10 \%$ of that equivalent to its rate of glucose consumption (as calculated from the relative free energies of combustion) (Thauer et al., 1977). However, the utilization of exogenous $\mathrm{H}_{2}$ did not significantly influence the specific rates of growth and consumption of glucose, or the molar growth yields (Fig. 2 and Table 2). A major difference between photoheterotrophic cultures supplemented with $\mathrm{H}_{2}$ and those lacking $\mathrm{H}_{2}$ in the gas phase was a higher $(26 \%)$ overall rate of $\mathrm{O}_{2}$ uptake in the former (Table 2).

Mean specific activities of $\mathrm{O}_{2}$ and $\mathrm{H}_{2}$ consumption determined for shorter time intervals (Fig. 3), instead of those calculated for the total $66 \mathrm{~h}$ growth period (Table 2 ), revealed the following interesting points. $\mathrm{O}_{2}$ consumption stayed relatively constant throughout the growth of cultures not supplemented with $\mathrm{H}_{2}$, the initial rates being very similar to those of $\mathrm{H}_{2}$-consuming cultures, despite the high $\mathrm{H}_{2}$ uptake activities of the latter. At the end of growth, however, there was a significant difference in the respective rates of $\mathrm{O}_{2}$ consumption under the two culture conditions, due to an increase of $\mathrm{O}_{2}$ uptake (about $60 \%$ ) in the $\mathrm{H}_{2}$-consuming

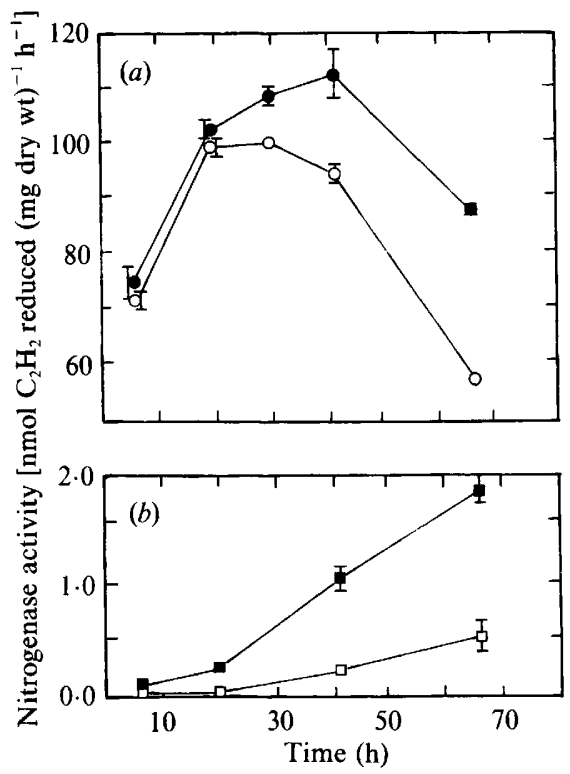

Fig. 4. (a) Nitrogenase activity (measured as specific rates of $\mathrm{C}_{2} \mathrm{H}_{2}$ reduction) in photoheterotrophic cultures of Nostoc sp. strain Cc grown in nickel-supplemented media with $(\bullet)$ or without $(\mathrm{O})$ added $\mathrm{H}_{2}$ $(10.5 \%, \mathrm{v} / \mathrm{v})$ in the gas phase. Growth and glucose consumption of these cultures are illustrated in Fig. $2 ; \mathrm{H}_{2}$ and $\mathrm{O}_{2}$ exchange of the cultures is illustrated in Fig. 3. (b) Nitrogenase activity in control cultures supplemented with DCMU, but lacking glucose with $(\square)$ and without ( $\square$ ) added $\mathrm{H}_{2}$. The values are means \pm SE (bars) of at least three replicates. Bars are not shown when smaller than the dimensions of the symbols. Results illustrated are typical of those obtained in three independent experiments.

cultures. In contrast, the mean specific rates of $\mathrm{H}_{2}$ uptake decreased as $\mathrm{H}_{2}$-consuming cultures increased in cell density.

In the absence of glucose, growth in the presence of DCMU was negligible both in the presence and absence of $\mathrm{H}_{2}$ in the gas phase, although $\mathrm{H}_{2}$ seemed to stimulate slightly the final growth yield (Fig. 2). The residual growth observed under these conditions was most likely due to the fact that $20 \mu \mathrm{M}$-DCMU does not completely abolish oxygenic photosynthesis in Nostoc sp. strain Cc (Table 2). However, a higher concentration of the herbicide could not be employed since it had toxic side effects, as evidenced by the fact that photoheterotrophic growth decreased considerably at DCMU concentrations above $20 \mu \mathrm{M}$.

Unlike growth, nitrogenase activity increased significantly in $\mathbf{H}_{2}$-supplemented photoheterotrophic cultures during a specific period (30-66 h) after the onset of the experiments (Fig. 4). Nitrogenase activity was also stimulated by $\mathrm{H}_{2}$ in the control cultures lacking glucose, but the mean specific rates of $\mathrm{C}_{2} \mathrm{H}_{2}$ reduction over the entire growth period were about 120 times lower than those observed under photoheterotrophic conditions (Table 2). 


\section{Table 3. Elemental composition of Nostoc sp. strain Cc}

Nostoc sp. strain Cc was collected at the end of the growth period (coinciding with the exhaustion of glucose) from photoheterotrophic, nickel-supplemented cultures grown with or without added $\mathrm{H}_{2}(10.5 \%, \mathrm{v} / \mathrm{v})$ in the gas phase. Growth parameters and gas exchange of these cultures are illustrated in Figs 2-4 and Table 2. Elemental analysis (CNHO) was performed on five replicate cultures as described in Methods. Mean values $( \pm \mathrm{SE})$ are given.

\begin{tabular}{lcccc}
\hline \hline & \multicolumn{4}{c}{$\begin{array}{c}\text { Elemental composition of the biomass } \\
\text { (\% ash-free dry wt) }\end{array}$} \\
\cline { 2 - 5 } Gas phase & $\mathrm{C}$ & $\mathrm{N}$ & $\mathrm{H}$ & $\mathrm{O}$ \\
\hline$+\mathrm{H}_{2}$ & $50 \cdot 9 \pm 0.2$ & $9 \cdot 7 \pm 0.3$ & $7 \cdot 4 \pm 0 \cdot 1$ & $32 \cdot 0 \pm 0 \cdot 4$ \\
$-\mathrm{H}_{2}$ & $49 \cdot 9 \pm 0.3$ & $8 \cdot 6 \pm 0 \cdot 2$ & $7 \cdot 4 \pm 0 \cdot 2$ & $34 \cdot 1 \pm 0 \cdot 3$ \\
\hline \hline
\end{tabular}

Since $\mathrm{C}_{2} \mathrm{H}_{2}$ reduction does not necessarily represent $\mathrm{N}_{2}$ fixation under all conditions (Daday \& Smith, 1987), we also determined the biomass and elemental composition of cultures grown in nickel-supplemented media, both with and without added $\mathbf{H}_{2}$ in the gas phase. For this, the cells were collected at the end of the growth period (coinciding with the exhaustion of glucose in the medium). $\mathrm{H}_{2}$-consuming cultures produced biomasses characterized by a significantly higher content of total nitrogen (Table 3).

Hydrogen also stimulated $\mathrm{NH}_{4}^{+}$excretion, which at the end of the experiments amounted to 7.8 and $6.9 \mathrm{mg} \mathrm{l}^{-1}$ in $\mathrm{H}_{2}$-supplemented and non- $\mathrm{H}_{2}$-supplemented cultures, respectively.

\section{Discussion}

Net $\mathbf{H}_{2}$ consumption or formation in photoheterotrophic, $\mathrm{N}_{2}$-fixing cultures of Nostoc sp. strain $\mathrm{Cc}$ was markedly dependent on the nickel ion content of the growth medium. This phenomenon has previously been observed in photoautotrophically grown cyanobacteria (Zhang et al., 1984; Daday et al., 1985). As discussed in preliminary reports (Tredici et al., 1988b,c), $\mathrm{H}_{2}$ uptake activity in nickel-supplemented cultures of Nostoc sp. strain $\mathrm{Cc}$ is observed both under photo- and chemoheterotrophic conditions. This contrasts with the general opinion that organic carbon prevents the synthesis or expression of uptake hydrogenase, a regulatory phenomenon observed in several different heterotrophic (Schlegel \& Eberhardt, 1972; Maier et al., 1979; Partridge et al., 1980) and phototrophic bacteria (Willison et al., 1983) and in one cyanobacterium (Kumar et al., 1986). However, Bradyrhizobium japonicum expresses uptake hydrogenase activity during heterotrophic growth (Graham et al., 1984; van Berkum, 1987). As suggested by van Berkum \& Maier (1988), changes in the $\mathrm{pH}$ of the medium or limitations in the availability of $\mathrm{O}_{2}$ caused by high rates of respiration may be involved in the degree of hydrogenase expression.

Our results clearly demonstrate a correlation between $\mathrm{H}_{2}$ consumption and an increase in the efficiency of $\mathrm{N}_{2}$ fixation ( $15 \%$ increase of $\mathrm{C}_{2} \mathrm{H}_{2}$ reduction over the whole period of growth) and $\mathrm{N}_{2}$ assimilation (13\% increase in the nitrogen content of the biomass).

Daday \& Smith (1987) did not find any significant increase in the rates of $\mathrm{C}_{2} \mathrm{H}_{2}$ reduction, in spite of uptake hydrogenase activity, in a cyanobacterial isolate from Macrozamia communis grown both auto- and heterotrophically. The discrepancy with our findings might either be due to the different isolates under study, or could possibly be the result of differences in the experimental protocol.

The beneficial effect of $\mathrm{H}_{2}$ on $\mathrm{C}_{2} \mathrm{H}_{2}$ reduction was particularly pronounced after about $40 \mathrm{~h}$ both under photoheterotrophic conditions (about $52 \%$ stimulation) and in the control cultures lacking glucose (about $300 \%$ stimulation). However, a small but significant stimulatory effect of $\mathrm{H}_{2}$ on nitrogenase activity manifested itself as early as about $30 \mathrm{~h}$, not only in the control cultures lacking glucose but also in the photoheterotrophic cultures, the latter of which should not have been limited in energy and reductant. This contrasts with reports on other cyanobacteria, in which hydrogen had little stimulatory effect on nitrogenase activity unless reductant starvation was induced (Bothe et al., 1978; Lambert \& Smith, 1981; Houchins, 1984).

$\mathrm{H}_{2}$ uptake activity in Nostoc sp. strain Cc seems to be stimulated by light since the rates of $\mathrm{H}_{2}$ consumption decreased at higher cell concentrations. A substantial light stimulation of uptake hydrogenase was also observed in a cyanobacterial isolate from Macrozamia communis by Daday \& Smith (1987) who postulated a light-dependent oxidation of $\mathrm{H}_{2}$ by $\mathrm{O}_{2}$. The situation in Nostoc sp. strain $\mathrm{Cc}$ seems to be more complex. From the rates of $\mathrm{H}_{2}$ and $\mathrm{O}_{2}$ consumption observed in cultures with and without added $\mathrm{H}_{2}$, it can be postulated that light intensity is one of the key factors in the regulation of uptake hydrogenase synthesis and/or activity and that, in contrast to the isolate from Macrozamia communis (Daday \& Smith, 1987), $\mathrm{H}_{2}$ uptake is coupled to $\mathrm{O}_{2}$ consumption only at lower light intensities (i.e. high cell densities).

The fact that the increase of the rate of $\mathrm{O}_{2}$ consumption and the stimulatory effect of $\mathrm{H}_{2}$ on $\mathrm{C}_{2} \mathrm{H}_{2}$ reduction coincide seems to indicate that $\mathrm{H}_{2}$ uptake is beneficial to nitrogenase activity only when it is coupled to $\mathrm{O}_{2}$ consumption.

In the more commonly studied heterocystous cyanobacteria the synthesis of the oxyhydrogenase seems to be 
restricted to the heterocysts, in which the enzyme is assumed to play a major role in the protection of the $\mathrm{O}_{2}$ sensitive enzyme complex nitrogenase, due to its $\mathrm{O}_{2}$ scavenging capacities (Houchins, 1984; Bothe \& Eisbrenner, 1978). Whether this applies also to the facultative photo- and chemoheterotrophic Nostoc sp. strain Cc described here remains an open question and more detailed investigations are required to reveal the precise mechanisms by which enhancement of $\mathrm{N}_{2}$ fixation and assimilation are achieved in this organism.

It is well known that nitrogen assimilation by a cyanobacterium in symbiosis is regulated in such a way that the bulk of fixed nitrogen is diverted to the host (Peters et al., 1986). Any factor which enhances the efficiency of $\mathrm{N}_{2}$ fixation and assimilation in a cultured cyanobiont can therefore be considered potentially important for the increased supply of fixed nitrogen to the natural host of this strain in the symbiotic association.

Our results showed that (i) cells of Nostoc sp. strain Cc growing photoheterotrophically can dissipate substantial amounts of energy and reductant as $\mathrm{H}_{2}$; (ii) consumption of exogenously supplied $\mathrm{H}_{2}$ under photoheterotrophic conditions does not affect growth but significantly increases the efficiency of molecular nitrogen incorporation and $\mathrm{NH}_{4}^{+}$excretion. Assuming that efficient recycling of $\mathrm{H}_{2}$ occurs also under chemoheterotrophic conditions, the prevalent nutritional status of the cyanobiont in the Cycas-Nostoc symbiosis (Bergersen et $a l ., 1965)$, it can be postulated that the host might profit significantly from the $\mathrm{H}_{2}$ uptake capability of the cyanobiont.

Thanks are due to Miss Paola Vannucci and Mr Domenico Mannelli for excellent technical help.

\section{References}

Bergersen, F. J., KenNedy, G. S. \& WittManN, W. (1965). Nitrogen fixation in the coralloid roots of Macrozamia communis L. Johnson. Australian Journal of Biological Science 18, 1135-1142.

VAN BERKUM, P. (1987). Expression of uptake hydrogenase and hydrogen oxidation during heterotrophic growth of Bradyrhizobium japonicum. Journal of Bacteriology 169, 4565-4569.

VAN BERKUM, P. \& MAIER, R. J. (1988). Lack of carbon substrate repression of uptake hydrogenase activity in Bradyrhizobium japonicum SR. Journal of Bacteriology 170, 1962-1964.

BOTHE, H. \& EISBRENNER, G. (1978). Aspects of hydrogen metabolism in blue-green algae. In Hydrogenases: Their Catalytic Activity, Structure and Function, pp. 353-369. Edited by H. G. Schlegel \& K. Schneider. Göttingen: Erich Goltze KG.

Bothe, H., Distler, E. \& Eisbrenner, G. (1978). Hydrogen metabolism in blue-green algae. Biochimie 60, 277-289.

DADAY, A. \& SMITH, G. D. (1987). The hydrogenase-nitrogenase relationship in a symbiotic cyanobacterium isolated from Macrozamia communis L. Johnson. Australian Journal of Plant Physiology 14, 319-324.

Daday, A., Mackerras, A. H. \& Smith, G. D. (1985). The effect of nickel on hydrogen metabolism and nitrogen fixation in the cyanobacterium Anabaena cylindrica. Journal of General Microbiology 131, 231-238.

Dixon, R. O. D. (1972). Hydrogenase in legume root nodule bacteroids: occurrence and properties. Archives of Microbiology 85, 193-201.

Graham, L. A., Stults, L. W. \& Maier, R. J. (1984). Nitrogenasehydrogenase relationships in Rhizobium japonicum. Archives of Microbiology 140, 243-246.

Houchins, J. P. (1984). The physiology and biochemistry of hydrogen metabolism in cyanobacteria. Biochimica et Biophysica Acta 768, $227-255$.

Kumar, A. P., Perraju, B. T. V. V. \& Singh, H. N. (1986). Carbon nutrition and the regulation of uptake hydrogenase activity in freeliving and symbiotic Anabaena cycadeae. New Phytologist 104, 115 120.

LAMBerT, G. R. \& SMith, G. D. (1981). The hydrogen metabolism of cyanobacteria (blue-green algae). Biological Reviews 56, 589-660.

MaIER, R. J., Hanus, F. J. \& Evans, H. J. (1979). Regulation of hydrogenase in Rhizobium japonicum. Journal of Bacteriology 137, 824-829.

Methods of Enzymatic Food Analysis (1984). UV-method for the determination of glucose and fructose in foodstuffs $\mathrm{C}$ and other materials, pp. 27-29. Mannheim, FRG: Boehringer-Mannheim.

Mortenson, L. E. \& THORneley, R. N. F. (1979). Structure and function of nitrogenase. Annual Review of Biochemistry 48, 387-418.

Papen, H., Kentemich, T., Schmülling, T. \& Bothe, H. (1986). Hydrogenase activities in cyanobacteria. Biochimie 68, 121-132.

Partridge, C. D. P., Walker, C. C., Yates, M. G. \& Postgate, J. R. (1980). The relationship between hydrogenase and nitrogenase in Azotobacter chroococcum: effect of nitrogen sources on hydrogenase activity. Journal of General Microbiology 119, 313-319.

Peters, G. A., Toia, R. E., JR, Calvert, H. E. \& MARsh, B. H. (1986). Lichens to Gunnera - with emphasis on Azolla. Plant and Soil 90 , $17-34$.

Rippka, R., Deruelles, J., Waterbury, J. B., Herdman, M. \& STANIER, R. Y. (1979). Generic assignments, strain histories and properties of pure cultures of cyanobacteria. Journal of General Microbiology 111, 1-61.

SCHLEGEL, H. G. \& EBERHARDT, U. (1972). Regulatory phenomena in the metabolism of Knallgas bacteria. Advances in Microbial Physiology 7, 205-242.

Stouthamer, A. H., Stam, H., De VRies, W. \& van Vlerken, M. (1988). Some aspects of nitrogen fixation in free-living cultures of Rhizobium. In Nitrogen Fixation: Hundred Years After. Proceedings of the 7th International Congress on Nitrogen Fixation, pp. 257-261. Edited by H. Bothe, F. J. de Bruijn \& W. E. Newton. Stuttgart: Gustav Fischer.

Tel-Or, E., LuiJk, L. W. \& Packer, L. (1977). An inducible hydrogenase in cyanobacteria enhances $\mathrm{N}_{2}$ fixation. FEBS Letters 78, $49-52$.

Thauer, R. K., Jungermann, K. \& Decker, K. (1977). Energy conservation in chemotrophic anaerobic bacteria. Bacteriological Reviews 41, 100-180.

Tredici, M. R., Margheri, M. C., Giovannetti, L., De PhilipPis, R. $\&$ VINCENZINI, M. (1988a). Heterotrophic metabolism and diazotrophic growth of Nostoc sp. from Cycas circinalis. Plant and Soil 110, 199-206.

Tredici, M. R., Margheri, M. C. \& De Philippis, R. (1988b). Hydrogen metabolism and heterotrophic growth in Nostoc sp. strain Cc. In Nitrogen Fixation: Hundred Years After. Proceedings of the 7th International Congress on Nitrogen Fixation, p. 219. Edited by $\mathrm{H}$. Bothe, F. J. de Bruijn \& W. E. Newton. Stuttgart: Gustav Fischer.

Tredici, M. R., Margheri, M. C., De PhilipPis, R. \& Materassi, R. (1988c). Hydrogen metabolism and photoheterotrophic growth in the symbiotic cyanobacterium Nostoc sp. strain Cc. Abstracts of the VI International Symposium on Photosynthetic Prokaryotes, Noordwijkerhout, The Netherlands, p. 52.

TURNER,G. L. \& Gibson, A. H. (1980). Measurement of nitrogen fixation by indirect means. In Methods for Evaluating Biological Nitrogen Fixation, pp. 111-138. Edited by F. J. Bergersen. New York: John Wiley. 
Willison, J. C., Jouanneau, Y., Michalski, W. P., Colbeau, A. \& VignaIS, P. M. (1983). Nitrogen fixation and $\mathrm{H}_{2}$ metabolism in the photosynthetic bacterium, Rhodopseudomonas capsulata. In Photosynthetic Prokaryotes, pp. 333-354. Edited by G. C. Papageorgiu \& L. Packer. New York: Elsevier.
Zhang, X., TABita, F. R. \& VAN BAALEN, C. (1984). Nickel control of hydrogen production and uptake in Anabaena spp. strains CA and 1F. Journal of General Microbiology 130, 1815-1818. 